\title{
ANALISA TESTIMONIAL DENGAN MENGGUNAKAN ALGORITMA TEXT MINING DAN TERM FREQUENCY- INVERSE DOCUMENT FREQUENCE (TF-IDF) PADA TOKO ALLMEEART
}

\author{
Meylita Putri Simatupang ${ }^{1}$, Dito Putro Utomo ${ }^{1}$ \\ ${ }^{1}$ Program Studi Teknik Informatika STMIK Budi Darma, Medan, Indonesia \\ Email: ${ }^{1}$ meylitaputri49@yahoo.com, ${ }^{1}$ ditoputro12@gmail.com
}

\begin{abstract}
Abstrak
E-commerce atau sering di sebut dengan online shop merupakan tren terbaru dari masyarakat dalam melakukan atifitas berbelanja, dulu sebelum maraknya perusahaan e-commerce seperti saat ini masyarakat untuk memenuhi kebutuhannya masih mengandalkan distro-distro sekitar customer tinggal, atau ke tempat perbelanjaan namun sekarang telah beralih ke online shoop. Kelebihan yang ditawarkan dari online shoop adalah harga yang relatif murah, tidak perlu ke lokasi toko, dan jamin barang, hal tersebut berdampak kepada toko-toko retail yang semakin lama semakin sepi. Testimonial merupakan salah satu teknik yang dilakukan untuk menyakinkan pelanggan berbelanja di e-commerce yang dimilikinya, testimonial merupakan tanggapan pembeli atas pengalamannya berbelanja di suatu aplikasi e-commerce mulai dari proses pembayaran sampai dengan barang diterima, semakin banyak pengalaman positif yang disampaikan pada testimonial maka pelanggan yang belum melakukan belanja pada suatu aplikasi e-commerce akan semakin yakin untuk berbelanja. Testimonial pada suatu aplikasi e-commerce tidak selamanya positif, ada kalanya testimonial yang disampaikan oleh pembeli negatif. Masalah customer adalah tidak tersedianya persentasi atau informasi jumah pembeli dengan pengalaman belanja yang positif dan negatif karena pada umumnya testimonial yang disampaikan hanya dalam bentuk daftar saja.
\end{abstract}

Kata Kunci: Analisa Testimonial, Algoritma Text Mining, Term Frequency-Inverse Document Frequency (TF-IDF)

\section{Abstract}

E-commerce or often referred to as an online shop is the latest trend of the community in carrying out shopping activities, fir st before the rise of e-commerce companies like today the community to meet their needs still rely on distros around the customer lives, or to a shopping place but now it has switch to shoop online. The advantages offered by online shoop are the relatively low prices, no need to shop locations, and guarantee goods, it has an impact on retail shops that are increasingly lonely. Testimonials are one of the techniques carried out to convince customers to shop at e-commerce they have, testimonials are the responses of buyers for their experience of shopping in an e-commerce application starting from the payment process until the goods are received, the more positive experiences conveyed in the testimonials, the customer who have not shopped on an e-commerce application will be more convinced to shop. Testimonials on an e-commerce application are not always positive, there are times when testimonials are delivered by negative buyers. The customer's problem is the unavailability of percentages or information on the number of buyers with positive and negative shopping experiences because in general testimonials are only delivered in the form of a list.

Keywords: Testimonial Analysis, Text Mining Algorithm, Term Frequency-Inverse Document Frequency (TF-IDF)

\section{PENDAHULUAN}

E-commerce atau sering di sebut dengan online shop allmeeart merupakan tren terbaru dari masyarakat dalam melakukan atifitas berbelanja, dulu sebelum maraknya perusahaan e-commerce seperti saat ini masyarakat untuk memenuhi kebutuhannya masih mengandalkan distro-distro sekitar customer tinggal, atau ke tempat perbelanjaan namun sekarang telah beralih ke online shoop allmeeart. Kelebihan yang ditawarkan dari online shoop allmeeart adalah harga yang relatif murah, tidak perlu ke lokasi toko, dan jamin barang, hal tersebut berdampak kepada toko-toko retail yang semakin lama semakin sepi.

Perkembangan yang sangat cepat dibidang penjualan pakaian online memberi pengaruh besar pada berbagai aspek kehidupan manusia. Seiring perkembangan teknologi yang semakin modern seperti sekarang ini membutuhkan algoritma yang dapat membantu kinerja penjualan terutama dalam bidang testimonial agar lebih baik dan maksimal untuk penjualan kedepannya.

Perusahaan e-commerce terus mengalami perkembangan, sampai dengan saat ini sudah lebih dari 50 perusahaan e-commerce yang terdaftar di Indonesia, dengan semakin tingginya jumlah aplikasi e-commerce di Indonesia maka semakin tinggi pula tingkat persaingannya. Testimonial merupakan salah satu teknik yang dilakukan untuk menyakinkan pelanggan berbelanja di e-commerce yang dimilikinya, testimonial merupakan tanggapan pembeli atas pengalamannya berbelanja di suatu aplikasi e-commerce mulai dari proses pembayaran sampai dengan barang diterima, semakin banyak pengalaman positif yang disampaikan pada testimonial maka pelanggan yang belum melakukan belanja pada suatu aplikasi e-commerce akan semakin yakin untuk berbelanja.

Testimonial pada suatu aplikasi e-commerce tidak selamanya positif, ada kalanya testimonial yang disampaikan oleh pembeli negatif. Masalah customer adalah tidak tersedianya persentasi atau informasi jumah pembeli dengan pengalaman belanja yang positif dan negatif karena pada umumnya testimonial yang disampaikan hanya dalam bentuk daftar saja. Hal tersebut tentunya akan merepotkan calon pembeli jika berpedoman terhadap persentase pengalaman berbelanja yang positif, oleh sebab itu dibutuhkan suatu teknik untuk menghasilkan informasi kepada customer berapa banyak testimonial dari customer sebelumnya dengan pengalaman berbelanja yang positif dan negatif.

Text Mining merupakan penerapan konsep dan teknik data mining untuk mencari pola dalam teks, proses penganalisaan teks guna menemukan informasi yang bermanfaat untuk tujuan tertentu. Defenisi lain yang berkaitan 
dengan Text Mining dikatakan bahwa Text Mining merupakan penambangan data yang berupa teks dimana sumber data biasanya didapatkan dari dokumen dan tujuannya adalah mencari kata-kata yang dapat mewakili isi dari dokumen sehingga dapat dilaku kan analisa keterhubungan antara dokumen [1]. Metode Term Frequency Invers Document Frequency (TF-IDF) merupakan metode yang digunakan menentukan seberapa jauh keterhubungan kata (term) terhadap dokumen dengan memberikan bobot setiap kata. Metode TF-IDF ini menggabungkan dua konsep yaitu frekuensi kemunculan sebuah kata di dalam sebuah dokumen dan inverse frekuensi dokumen yang mengandung kata tersebut [2].

Penulis menerapkan algoritma Text Mining untuk mengindentifikasi testimonial berdasarkan penelitian yang dilakukan oleh Bening Herwijayanti, Dian Eka Ratnawati dan Lailil Muflikhah dengan judul "Klasifikasi berita oneline dengan menggunakan pembobotan TF-IDF dan cosine similarity" menyimpulkan bahwa "Untuk menerapkan pengelompokan berita online dengan menggunakan algoritma single pass clustering memerlukan proses preprocessing yaitu tokenizing, stopword dan stemming. preprocessing tersebut dapat memperkecil term sehingga bisa mempercepat proses perhitungan pembobotan term menggunakan TF-IDF dan mempercepat proses cosine similarity. dan penelitian yang dilakukan oleh Bambang Kurniawan, Syahril Effendi, Opim Salim Sitompul, dengan judul "Klasifikasi Konten Berita Dengan Metode Text Mining" menyimpulkan bahwa "dari hasil pengujian algoritma Text Mining mampu melakukan proses klasifikasi data berita secara otomatis dan proses klasifikasi semakin akurat jika data latih yang digunakan dalam pembelajaran dalam jumlah banyak [5].

\section{TEORITIS}

\subsection{Testimonial}

Testimonial adalah komentar-komentar atau pendapat dari konsumen mengenai produk atau jasa yang telah di beli nya , kemudian pendapat tersebut di sebarluaskan, dalam bidang periklanan, testimonial sering di gunakan untuk menarik minat dari konsumen, penggunaan testimonial dapat di terapkan melalui berbagai cara, seperti dengan memberikan testimonial pada orang ahli, artis atau orang biasa untuk menceritakan atau berbagi pengalaman terhadap suatu produk yang telah di beli atau di gunakan nya [4].

\subsection{Text Mining}

Text mining dapat didefinisikan secara luas sebagai proses pengetahuan intensif di mana pengguna berinteraksi dengan koleksi dokumen dari waktu ke waktu dengan menggunakan seperangkat alat analisis. Text mining berusaha untuk mengekstrak informasi yang berguna dari sumber data melalui identifikasi dan eksplorasi pola yang menarik. Text mining banyak mengarah pada bidang penelitian data mining. Oleh karena itu, tidak mengherankan bahwa text mining dan data mining akan berada pada tingkat arsitektur yang sama [1].

\subsection{Term Frequency- Inverce Document Frequency(TF-IDF)}

Data yang telah melalui tahap preprocessing harus berbentuk numerik. Untuk mengubah data tersebut menjadi numerik yaitu menggunakan metode pembobotan TF-IDF merupakan metode yang digunakan menetukan seberapa jauh keterhubungan kata (term) terhadap dokumen dengan memberikan bobot setiap kata. Metode TF-IDF ini menggabungkan dua konsep yaitu frekuensi kemunculan sebuah kata di dalam sebuah dokumen dan inverse frekuensi dokumen yang mengandung kata tersebut [6].

Dalam perhitungan bobot menggunakan TF-IDF, dihitung terlebih dahulu nilai TF perkata dengan bobot masing-masing kata adalah 1. Sedangkan nilai IDF diformulasikan pada persamaan (1).

$$
I D F(\text { word })=\log \frac{t d}{d f}
$$

IDF (word) adalah nilai IDF dari setiap kata yang akan di cari, td adalah jumlah keseluruhan dokumen yang ada, df jumlah kemunculan kata pada semua dokumen.

\section{ANALISA DAN PEMBAHASAN}

Testimonial merupakan salah satu teknik yang dilakukan untuk menyakinkan pelanggan berbelanja di ecommerce yang dimilikinya, Testimonial pada suatu aplikasi e-commerce tidak selamanya positif, ada kalanya testimonial yang disampaikan oleh pembeli negatif. Masalah yang dihadapi oleh calon pembeli adalah tidak tersedianya persentasi atau informasi jumah pembeli dengan pengalaman belanja yang positif dan negatif karena pada umumnya testimonial yang disampaikan hanya dalam bentuk daftar saja. Hal tersebut tentunya akan merepotkan calon pembeli jika berpedoman terhadap persentase pengalaman berbelanja yang positif, oleh sebab itu dibutuhkan suatu teknik untuk menghasilkan informasi berapa banyak testimonial dari pembeli sebelumnya dengan pengalaman berbelaja yang positif dan negatif.

Text mining merupakan penerapan konsep dan teknik data mining untuk mencari pola dalam teks, proses penganalisaan teks guna menemukan informasi yang bermanfaat untuk tujuan tertentu, Sedangkan algoritma Term Frequency Invers DocumentFrequency (TF-IDF) merupakan metode yang digunakan menentukan seberapa jauh keterhubungan kata (term) terhadap dokumen dengan memberikan bobot setiap kata. Penerapan dari kedua algoritma 
tersebut dibagi menjadi algoritma text mining digunakan sebagai penolahan teks dari setiap testimoni, hasil dari algoritma tersebut akan menghasilkan kata-kata akar (root) dari setiap testimoni. Kata-kata akar tersebut akan dibandingkan dengan kata-kata yang mengandung konotasi positif dan konotasi negatif dengan menggunakan algoritma Term Frequency Invers Document Frequency (TF-IDF). Hasil dari algoritma TF-IDF berupa bobot kesesuaian atas kata-kata konotasi negatif dan positif yang telah ditentukan. Penerapan dari algoritma text mining dan algoritma Term Frequency Invers Document Frequency (TF-IDF) dapat dilihat pada gambar 1.

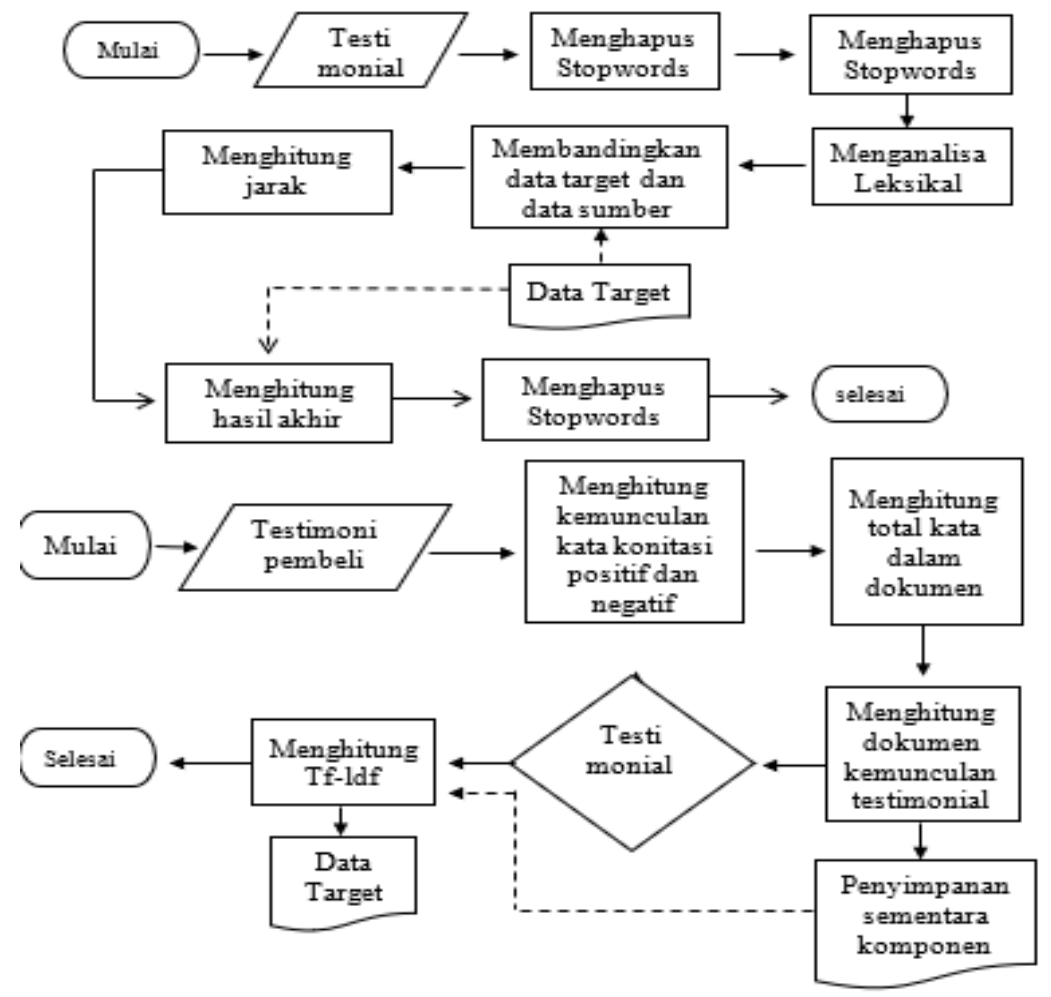

Gambar 1. Skema Penerapan Algoritma Text Mining

\subsection{Penerapan Algoritma Text Mining dan Term Frequency Inverse Document Frequence (TF-IDF)}

Untuk menganalisa testimoni pembeli atas pengalaman belanjanya, maka langkah awal yang dilakukan penulis adalah mengumpulkan data testimoni dari suatu situs $e$-commerce, dalam hal ini penulis memanfaatkan teknik web data extraction. Untuk memudahkan dalam melakukan penerapan algoritma tersebut dalam melakukan analisa testimonial pembeli, maka penulis hanya mengambil data testimoni sebanyak 40 saja, data tersebut dapat dilihat pada tabel 1.

Tabel 4.1 Data Testimoni

\begin{tabular}{|c|c|c|}
\hline Kode & $\begin{array}{l}\text { Nama } \\
\text { Customer }\end{array}$ & Testimonial \\
\hline D1 & Ima & $\begin{array}{l}\text { Respon chat cepat. Packing baik. Recommended seller. } \\
\text { Cepat sampai. Barang sesuai pesanan }\end{array}$ \\
\hline D2 & Yani & $\begin{array}{l}\text { Senang dengan layanan Pelapak dan akan berbelanja lagi } \\
\text { di sini. }\end{array}$ \\
\hline D3 & Reni & Respon \& barang nya oke bgt, terimakasih \\
\hline D4 & Dorma & $\begin{array}{l}\text { Senang dengan layanan Pelapak dan akan berbelanja lagi } \\
\text { di sini. }\end{array}$ \\
\hline D5 & Velika & $\begin{array}{l}\text { Barang Ok, sesuai pesanan, packing ajib aman dan sangat } \\
\text { rapi, Seller Asik, Pokoknya Recommended lah }\end{array}$ \\
\hline D6 & Evelyn & $\begin{array}{l}\text { Recommended Seller, Cepat sampai, Pelapak Ramah, } \\
\text { Respon Cepat, dan Kualitas Barang mantap }\end{array}$ \\
\hline D7 & Panogari & $\begin{array}{l}\text { Pengiriman cepat, kemasan rapi, barang ori dan bagus. } \\
\text { Terima kasih Mbak Yani. Good job }\end{array}$ \\
\hline D8 & Riska & $\begin{array}{l}\text { Barang sesuai pesanan respon cepat makasih ya gan } \\
\text { semoga sukses }\end{array}$ \\
\hline D9 & Edi & Responsif dan komunikatif. Saya puas dengan seller ini \\
\hline D10 & Hendra & Respon chat lambat, barang lama sampai \\
\hline
\end{tabular}




\begin{tabular}{|c|c|c|}
\hline D11 & Ridho & $\begin{array}{l}\text { Barang kurang memuaskan tidak sesuai dengan dekripsi } \\
\text { barang }\end{array}$ \\
\hline D12 & Madi & $\begin{array}{l}\text { Pengiriman barang sangat lama, kecewa saya dengan } \\
\text { pelayannya }\end{array}$ \\
\hline D13 & Dayat & $\begin{array}{l}\text { Kurang memuaskan pengirimannya, tidak sesuai dengan } \\
\text { waktu estimasi yang disampaikan }\end{array}$ \\
\hline D14 & Wilson & Barang yang saya terima lecet, packing kurang baik \\
\hline D15 & Andre & Barang sesuai pesanan, semoga ada promo lagi \\
\hline
\end{tabular}

Setelah data dikumpulkan maka tahapan selanjutnya dari algoritma text mining adalah sebagai berikut :

1. Case Folding

Adapun tahapan yang dilakukan pada algoritma Teks Mining diawali dengan melakukan proses Case Folding, yaitu melakukan perubahan string menjadi huruf kecil. Hasil dari proses case folding dapat dilihat pada paragraf dibawah ini.

Tabel 2. Hasil Tahapan Case Folding

\begin{tabular}{cc}
\hline Kode & Testimonial \\
\hline D1 & $\begin{array}{c}\text { respon chat cepat. packing baik. recommended seller. cepat sampai. barang sesuai } \\
\text { pesanan }\end{array}$ \\
D2 & senang dengan layanan pelapak dan akan berbelanja lagi di sini. \\
D3 & respon \& barang nya oke banget, terimakasih \\
D4 & senang dengan layanan pelapak dan akan berbelanja lagi di sini. \\
D5 & barang ok, sesuai pesanan, packing ajib aman dan sangat rapi, seller asik, pokoknya \\
& recommended lah \\
D6 & recommended seller, cepat sampai, pelapak ramah, respon cepat, dan kualitas barang \\
& mantap \\
D7 & pengiriman cepat, kemasan rapi, barang ori dan bagus. terima kasih mbak yani. good job \\
D8 & barang sesuai pesanan respon cepat makasih ya gan semoga sukses \\
D9 & responsif dan komunikatif. saya puas dengan seller ini \\
D10 & respon chat lambat, barang lama sampai \\
D11 & barang kurang memuaskan tidak sesuai dengan dekripsi barang \\
D12 & pengiriman barang sangat lama, kecewa saya dengan pelayannya \\
D13 & kurang memuaskan pengirimannya, tidak sesuai dengan waktu estimasi yang \\
& disampaikan \\
D14 & barang yang saya terima lecet, packing kurang baik \\
D15 & barang yang saya terima lecet, packing kurang baik
\end{tabular}

\section{Tokenizing}

Tahap tokenizing adalah tahap pemotongan string menjadi potongan kata kemudian disusun menjadi baris. Tahap tersebut dapat dilihat dibawah ini.

Tabel 3. Hasil Tahapan Tokenizing

\begin{tabular}{cc}
\hline Kode & Testimonial \\
\hline D1 & respon chat cepat. packing baik. recommended seller. cepat sampai. barang sesuai \\
pesanan. & senang. dengan layanan pelapak. dan akan berbelanja. lagi di sini. \\
D2 & respon \& barang nya oke banget, terimakasih. \\
D3 & senang. dengan layanan pelapak. dan akan berbelanja. lagi di sini. \\
D4 & barang ok, sesuai pesanan, packing ajib aman dan sangat rapi, seller asik, pokoknya \\
D5 & recommended lah. \\
D6 & recommended seller, cepat sampai, pelapak ramah, respon cepat, dan kualitas barang \\
mantap. & pengiriman cepat, kemasan rapi, barang ori dan bagus. terima kasih mbak yani. good job. \\
D7 & barang sesuai pesanan. respon cepat. makasih ya gan.semoga sukses. \\
D9 & responsif dan komunikatif. saya puas dengan seller ini. \\
D10 & respon chat lambat, barang lama sampai. \\
D11 & barang kurang memuaskan. tidak sesuai. dengan dekripsi barang. \\
D12 & pengiriman barang sangat lama, kecewa saya dengan pelayannya. \\
D13 & kurang memuaskan pengirimannya, tidak sesuai dengan waktu estimasi yang \\
& disampaikan.
\end{tabular}


D14 barang yang saya terima lecet, packing kurang baik.

D15 barang sesuai pesanan, semoga promo.

\section{Filtering}

Pada tahapan ini akan dilakukan pengahapusan kata yang tidak penting atau disebut dengan stop word, dalam hal ini penulis memanfaatkan library tala, beberapa daftar kata stop word sebagai berikut : ada, adalah, adanya, adapun, akan, akankah, akhir, akhiri, akhirnya, aku, akulah, amat, amatlah, anda, andalah, antar, antara, dll.Hasil dari menghilangkan kata stop word dari berita dapat dilihat pada paragraf dibawah ini :

Tabel 4. Hasil Tahapan Filtering

\begin{tabular}{cl}
\hline Kode & \multicolumn{1}{c}{ Testimonial } \\
\hline D1 & respon chat cepat packing recommended seller cepat barang sesuai pesanan \\
D2 & senang. layanan pelapak. berbelanja. \\
D3 & respon \& barang nya oke banget, terimakasih. \\
D4 & senang. layanan pelapak. berbelanja. sini. \\
D5 & barang ok, sesuai pesanan, packing ajib aman rapi, seller asik, pokoknya recommended \\
& lah. \\
D6 & recommended seller, cepat, pelapak ramah, respon cepat, kualitas barang mantap. \\
D7 & pengiriman cepat, kemasan rapi, barang ori bagus. terima kasih mbak yani. good job. \\
D8 & barang sesuai pesanan. respon cepat. makasih ya gan.semoga sukses. \\
D9 & responsif komunikatif. puas seller. \\
D10 & respon chat lambat, barang. \\
D11 & barang memuaskan. sesuai. dekripsi barang. \\
D12 & pengiriman barang, kecewa pelayannya. \\
D13 & kurang memuaskan pengirimannya, sesuai estimasi. \\
D14 & barang terima lecet, packing. \\
D15 & barang sesuai pesanan, semoga promo. \\
\hline
\end{tabular}

\section{Stemming}

Pada tahapan dilakukan proses mentransformasikan kata-kata yang menggunakan aturan tertentu seperti menghilangkan awalan dan ahiran untuk mendapatkan kata-kata akarnya atau disebut dengan root. Hasil dari proses stemming dapat dilihat pada paragraf dibawah ini :

Tabel 5. Hasil Tahapan Stemming

\begin{tabular}{cl}
\hline Kode & \multicolumn{1}{c}{ Testimonial } \\
\hline D1 & respon chat cepat pack recommend seller cepat barang sesuai pesan \\
D2 & senang. layan pelapak.belanja. \\
D3 & respon \& barang nya oke banget, terimakasih. \\
D4 & senang. layan lapak. belanja. sini. \\
D5 & barang ok, sesuai pesan, packing ajib aman rapi, seller asik, pokok recommend lah. \\
D6 & recommend seller, cepat, pelapak ramah, respon cepat, kualitas barang mantap. \\
D7 & pengirim cepat, kemas rapi, barang ori bagus. terima kasih mbak yani. good job. \\
D8 & barang sesuai pesan. respon cepat. makasih ya gan.semoga sukses. \\
D9 & responsif komunikatif. puas seller. \\
D10 & respon chat lambat, barang. \\
D11 & barang memuas. sesuai. dekripsi barang. \\
D12 & pengirim barang, kecewa pelayan. \\
D13 & kurang memuas pengiriman, sesuai estimasi. \\
D14 & barang terima lecet, packing. \\
D15 & barang sesuai pesanan, semoga promo. \\
\hline
\end{tabular}

\section{Spelling Normalization}

Tahapan selling normalization adalah perbaikan dan subtitusi kata-kata yang salah eja ataupun disingkat dengan bentuk tertentu. Hasil dari tahapan spelling normalization dapat dilihat pada paragraf dibawah ini.

Tabel 6. Hasil Tahapan Spelling Normalization

\begin{tabular}{cl}
\hline Kode & \multicolumn{1}{c}{ Testimonial } \\
\hline D1 & respon chat cepat pack recommend seller cepat barang sesuai pesan \\
D2 & senang. layan pelapak. belanja. \\
D3 & respon \& barang nya oke banget, terimakasih. \\
D4 & senang. layanan pelapak. belanja. sini. \\
D5 & barang ok, sesuai pesan, packing ajib aman rapi, seller asik, pokok recommend lah.
\end{tabular}


D6 recommend seller, cepat, pelapak ramah, respon cepat, kualitas barang mantap.

D7 pengirim cepat, kemas rapi, barang ori bagus. terima kasih mbak yani. good job.

D8 barang sesuai pesan. respon cepat. makasih ya gan.semoga sukses.

D9 responsif komunikatif. puas seller.

D10 respon chat lambat, barang.

D11 barang memuas. sesuai. dekripsi barang.

D12 pengirim barang, kecewa pelayan.

D13 kurang memuas pengiriman, sesuai estimasi.

D14 barang terima lecet, packing.

D15 barang sesuai pesanan, semoga promo.

\subsection{Analyzing}

Analyzing merupakan tahap penentuan seberapa jauh keterhubungan antar kata-kata dokumen yang ada. Untuk memudahkan analisa keterhubungan antar kata-kata pada setiap testimony maka penulis menerapkan algoritma term frequency-inverse document frequency (TF-IDF). Algoritma tersebut akan membantu penulis dalam menganalisa hubungan antara masing-masing frase/kalimat dari setiap testimonial dengan kata-kata yang mengandung konotasi positif dan konotasi negatif. Sebagai data target yang digunakan pada algoritma TF-IDF maka penulis telah menentukan kata-kata yang mengandung konotasi positif dan konotasi negatif yang dapat dilihat pada tabel dibawah ini.

Tabel 7. Kata-kata Konotasi Positif dan Negatif

\begin{tabular}{lll}
\hline & Konotasi Positif & Konotasi Negatif \\
\hline Cepat & Lambat \\
Sesuai & Kurang \\
Senang & Lama \\
Rapi & Tidak \\
Bagus & Kecewa \\
\hline
\end{tabular}

Hasil dari keterkaitan frase/kalimat testimonial yang belum diketahui apakah mengandung konotasi positif atau negatif dengan menerapkan algoritma TF-IDF dapat dilihat pada tabel 4.8 di bawah ini:

Tabel 8. Term Frekuansi dari masing-masing testimonial

\begin{tabular}{|c|c|c|c|c|c|c|c|c|c|c|c|c|c|c|c|c|c|c|c|}
\hline \multirow{2}{*}{$\mathbf{Q}$} & \multicolumn{15}{|c|}{ tf } & \multirow{2}{*}{ df } & \multirow{2}{*}{$\frac{D}{d f}$} & \multirow{2}{*}{ idf } & \multirow{2}{*}{ idf +1} \\
\hline & d1 & d2 & d3 & d4 & d5 & d6 & d7 & $\mathrm{d} 8$ & d9 & d10 & d11 & 112 & 13 & 14 & 115 & & & & \\
\hline Cepat & 2 & 0 & 0 & 0 & 0 & 2 & 1 & 1 & 0 & 0 & 0 & 0 & 0 & 0 & 0 & 4 & 3.75 & 0.574 & 1.574 \\
\hline sesuai & 1 & 0 & 0 & 0 & 1 & 0 & 0 & 1 & 0 & 0 & 1 & 0 & 1 & 0 & 1 & 6 & 2.5 & 0.397 & 1.397 \\
\hline Senang & 0 & 1 & 0 & 1 & 0 & 0 & 0 & 0 & 0 & 0 & 0 & 0 & 0 & 0 & 0 & 2 & 7.5 & 0.875 & 1.875 \\
\hline Rapi & 0 & 0 & 0 & 0 & 1 & 0 & 1 & 0 & 0 & 0 & 0 & 0 & 0 & 0 & 0 & 2 & 7.5 & 0.875 & 1.875 \\
\hline Bagus & 0 & 0 & 0 & 0 & 0 & 0 & 1 & 0 & 0 & 0 & 0 & 0 & 0 & 0 & 0 & 1 & 15 & 1.176 & 2.176 \\
\hline Lambat & 0 & 0 & 0 & 0 & 0 & 0 & 0 & 0 & 0 & 0 & 0 & 0 & 0 & 0 & 0 & 0 & 0 & 0 & 0 \\
\hline Kurang & 0 & 0 & 0 & 0 & 0 & 0 & 0 & 0 & 0 & 0 & 0 & 0 & 1 & 0 & 0 & 1 & 15 & 1.176 & 2.176 \\
\hline Lama & 0 & 0 & 0 & 0 & 0 & 0 & 0 & 0 & 0 & 0 & 0 & 0 & 0 & 0 & 0 & 0 & 0 & 0 & 0 \\
\hline Tidak & 0 & 0 & 0 & 0 & 0 & 0 & 0 & 0 & 0 & 0 & 0 & 0 & 0 & 0 & 0 & 0 & 0 & 0 & 0 \\
\hline Kecewa & 0 & 0 & 0 & 0 & 0 & 0 & 0 & 0 & 0 & 0 & 0 & 1 & 0 & 0 & 0 & 1 & 15 & 1.176 & 2.176 \\
\hline
\end{tabular}

Tabel 9. Hasil pembobotan dari masing-masing testimonial

\begin{tabular}{|c|c|c|c|c|c|c|c|c|c|c|c|c|c|c|}
\hline \multicolumn{15}{|c|}{$W=t f *(I D F+1)$} \\
\hline D1 & D2 & D3 & D4 & D5 & D6 & D7 & D8 & D9 & D10 & D11 & D12 & D13 & D14 & D15 \\
\hline 3.148 & 0 & 0 & 0 & 0 & 3.148 & 1.574 & 1.574 & 0 & 0 & 0 & 0 & 0 & 0 & 0 \\
\hline 1.397 & 0 & 0 & 0 & 1.397 & 0 & 0 & 1.397 & 0 & 0 & 1.397 & 0 & 1.397 & 0 & 1.397 \\
\hline 0 & 1.875 & 0 & 1.875 & 0 & 0 & 0 & 0 & 0 & 0 & 0 & 0 & 0 & 0 & 0 \\
\hline 0 & 0 & 0 & 0 & 1.875 & 0 & 1.875 & 0 & 0 & 0 & 0 & 0 & 0 & 0 & 0 \\
\hline 0 & 0 & 0 & 0 & 0 & 0 & 2.176 & 0 & 0 & 0 & 0 & 0 & 0 & 0 & 0 \\
\hline 0 & 0 & 0 & 0 & 0 & 0 & 0 & 0 & 0 & 0 & 0 & 0 & 0 & 0 & 0 \\
\hline 0 & 0 & 0 & 0 & 0 & 0 & 0 & 0 & 0 & 0 & 0 & 0 & 2.176 & 0 & 0 \\
\hline 0 & 0 & 0 & 0 & 0 & 0 & 0 & 0 & 0 & 0 & 0 & 0 & 0 & 0 & 0 \\
\hline 0 & 0 & 0 & 0 & 0 & 0 & 0 & 0 & 0 & 0 & 0 & 0 & 0 & 0 & 0 \\
\hline 0 & 0 & 0 & 0 & 0 & 0 & 0 & 0 & 0 & 0 & 0 & 2.176 & 0 & 0 & 0 \\
\hline 4.545 & 1.875 & 0 & 1.875 & 3272 & 3.148 & 5.625 & 2.971 & 0 & 0 & 1.397 & 2.176 & 3573 & 0 & 1.397 \\
\hline
\end{tabular}

Dari hasil perhitungan algoritma TF-IDF menunjukkan bobot untuk kata dengan konotasi positif sebesar 27.484 dan konotasi negatif sebesar 36.206 maka untuk menentukan persentasi dari sentiment masyarakat penulis menggunakan rumus sbb :

$$
\text { sentimen } x=\frac{100}{\text { sentimen positif }+ \text { sentimen negatif }} x \text { sentimen }
$$

Sentimen positif 


$$
\text { Sentimen Postif }=\frac{100}{27.484+36.206} \times 36.206=56.84 \%
$$

Sentiment Negatif

$$
\text { Sentimen Negatif }=\frac{100}{36.206+27.484} \times 27.484=43.15 \%
$$

Dari hasil penerapan algoritma text mining dan algoritma TF-IDF pada anilisa testimonial pada Toko Allmeeart dari setiap produk di websitenya, maka penulis telah melakukan pengujian terhadap masing-masing produk sebanyak 10 kali, maka didapatkanlah hasil sebagai berikut :

Tabel 10. Hasil Pengujian

\begin{tabular}{clcc}
\hline No & \multicolumn{1}{c}{ Testimoni } & Positif & Negatif \\
\hline 1. & Gamis az-zahra & $25 \%$ & $10 \%$ \\
2. & Gamis arniz & $20 \%$ & $5 \%$ \\
3. & Pakaian koko & $25 \%$ & $5 \%$ \\
4. & Sepatu adidas & $15 \%$ & $10 \%$ \\
5. & Jilbab az-zahra & $20 \%$ & $5 \%$ \\
6. & Tas channel & $25 \%$ & $5 \%$ \\
7. & Tas kosmetik & $25 \%$ & $10 \%$ \\
8. & Gamis otte hijab & $20 \%$ & $5 \%$ \\
9. & Jam tangan & $20 \%$ & $10 \%$ \\
10. & Jilbab mayra & $15 \%$ & $10 \%$ \\
\hline
\end{tabular}

Dari tabel hasil pengujian tersebut terbukti bahwa algoritma text mining dan algoritma TF-IDF dapat menganalisa konotasi positif dan negatif pada testimonial masing-masing produk.

\section{KESIMPULAN} berikut:

Dari berbagai penjelasan yang telah diuraikan dalam laporan, maka dapat disimpulkan berbagai hal sebagai

1. Algoritma text mining dan term frequency - inverse document frequency (TF-IDF) mampu melakukan klasifikasi testomoni dengan konotasi positif dan negative

2. Terjadi Overlap similarity dikarenakan pada tahapan steaming pada algoritma text mining masih dilakukan secara manual.

3. Semakin banyak ditentukan kata yang mengandung kata konotasi positif dan negatif maka hasil yang didapatkan menjadi lebih baik.

\section{REFERENCES}

[1] W. F. Kusuma, "Pengembangan Halaman Web Menggunakan Xml,” J. Tek. Inform., vol. 6, no. 2, 2015.

[2] P. S. Hasugian, "Website Sebagai Media Promosi," Peranc. WEBSITE SEBAGAI MEDIA PROMOSI DAN Inf. Penda, vol. 3, no. 1, pp. 82-86, 2018.

[3] P. Perancangan, "Perancangan Desain Website Sebagai Salah Satu Media Promosi the Cobbler Yogyakarta," pp. 1-22, 2017.

[4] R. I. Darmawan and A. H. Setianingrum, “1574-3879-1-Pb,” vol. 5341, no. April, pp. 53-62, 2018.

[5] A. Prayitno, A. Johar, and Y. Setiawan, "Implementasi algoritma turbo boyer moore pada aplikasi kamus istilah biologi berbasis android," vol. 6, no. 1, pp. 13-23, 2018.

[6] G. G. Maulana, "Pembelajaran Dasar Algoritma Dan Pemrograman Menggunakan El-Goritma Berbasis Web," J. Tek. Mesin, vol. 6, no. 2, p. 8, 2017.

[7] P. Translator, B. Pascal, D. Effendi, T. Hartono, and A. Kurnaedi, "Penerapan String Matching," vol. 11, no. 2, pp. $262-275$.

[8] M. Noorfaik and S. Novianto, "Efisiensi Penggunaan Algoritma Boyer Moore untuk Prediksi Perilaku Orang melalui Interaksi di Twitter."

[9] A. A. Zabar and F. Novianto, "KEAMANAN HTTP DAN HTTPS BERBASIS WEB MENGGUNAKAN SISTEM OPERASI KALI LINUX Program Studi Teknik Komputer - FTIK Universitas Komputer Indonesia Jurnal Ilmiah Komputer dan Informatika ( KOMPUTA ),”Ilm. Komput. dan Inform., vol. 4, no. ISSN : 2089-9033, pp. 69-74, 2015.

[10] R. Hidayatullah, "Pembuatan Desain Website Sebagai Penunjang Company Profile CV. Hensindo.," pp. 11-25, 2016. 